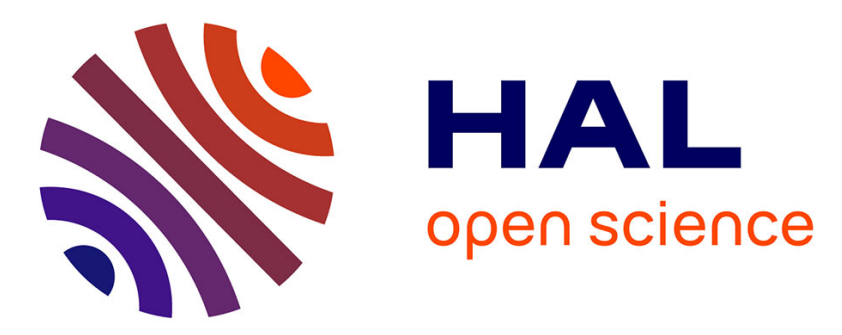

\title{
Hierarchical components of physical frailty predicted incidence of dependency in a cohort of elderly women.
}

Isabelle Carrière, Alain Colvez, Francois Favier, Claude Jeandel, Hubert Blain

\section{To cite this version:}

Isabelle Carrière, Alain Colvez, Francois Favier, Claude Jeandel, Hubert Blain. Hierarchical components of physical frailty predicted incidence of dependency in a cohort of elderly women.. Journal of Clinical Epidemiology, 2005, 58 (11), pp.1180-7. 10.1016/j.jclinepi.2005.02.018 . inserm-00108731

\section{HAL Id: inserm-00108731 https://www.hal.inserm.fr/inserm-00108731}

Submitted on 23 Oct 2006

HAL is a multi-disciplinary open access archive for the deposit and dissemination of scientific research documents, whether they are published or not. The documents may come from teaching and research institutions in France or abroad, or from public or private research centers.
L'archive ouverte pluridisciplinaire HAL, est destinée au dépôt et à la diffusion de documents scientifiques de niveau recherche, publiés ou non, émanant des établissements d'enseignement et de recherche français ou étrangers, des laboratoires publics ou privés. 


\title{
Hal author manuscript
}

J Clin Epidemiol 11/2005; 58(11): 1180-7

Hierarchical components of physical frailty predict incidence of dependency in a cohort of elderly women.

\author{
Isabelle Carrière ${ }^{1}$, Alain Colvez ${ }^{1}$, Francois Favier ${ }^{2}$, Claude Jeandel ${ }^{3}$, Hubert Blain ${ }^{3}$ \\ for the EPIDOS study group*
}

\section{Corresponding author/reprint request:}

Isabelle Carrière, INSERM Unité 500, 39 avenue Charles Flahault, 34093 MONTPELLIER CEDEX 5, FRANCE. Tel: (33) 4996146 91; Fax: (33) 4996145 79; e-mail: carriere@montp.inserm.fr 
${ }^{1}$ INSERM U500, 39 avenue Charles Flahault, 34093 Montpellier Cedex, France

${ }^{2}$ INSERM CIC-EC, Groupe Hospitalier Sud Réunion, 97410 Saint Pierre, France

${ }^{3}$ Department of Internal Medicine and Geriatrics, Montpellier University Hospital, 34295 Montpellier Cedex 5, France

* Members of the EPIDOS study group: Coordinators: G. Bréart, P. Dargent-Molina (epidemiology), P.J. Meunier, A.M. Schott (clinical aspects), D. Hans (bone densitometry and ultrasound quality control), P.D. Delmas (biochemistry). Principal investigators (center): C. Baudoin, J.L. Sebert (Amiens), M.C. Chapuy, A.M. Schott (Lyon); F. Favier, C. Marcelli (Montpellier); E. Hausherr, C.J. Menkes, C. Cormier (Paris); H. Grandjean, C. Ribot (Toulouse) 


\section{ABSTRACT}

Objective: to identify the most important predictors of early disability incidence and devise a simple score of physical frailty.

Methods: a cohort of 545 high-functioning women aged 75 years and older was followed for seven years. Every year, the self-reported loss of at least one instrumental activity of daily living was chosen as definition of disability. An extension of the logistic regression for repeated responses, the random-effect model, was used to assess the effects of baseline predictors. The regression coefficients of the final multivariate model were scaled and rounded to create a practical score.

Results: the proportion of women reporting disability increased from 22.1 percent to 52.1 percent throughout the follow-up. In the multivariate model increasing age, lower performances in mobility and balance tests, bad perceived health, lower muscle strength, higher body mass index, lower educational level, lower reported physical activity were strong predictors of disability. Evaluating the predictive value of the simplified predictive score on an independent cohort gave a c-statistic equal to 0.71 .

Conclusion: the use of a powerful fitting method allows to establish a hierarchy between the components of physical frailty and to provide a predictive score with substantial practical value for clinicians and public health professionals.

Key-words: longitudinal studies; logistic models; random-effects models; disability evaluation; frail elderly 
One important public health goal for an aging society is to minimize the impact of chronic diseases and impairments on the health status of older adults, to prevent dependency, and to improve their quality of life. If progress in medical care, together with better life conditions, account for a longer life span, the counterpart is that the number of very old people at risk of becoming disabled is increasing. Several studies suggest that the prevalence of moderate disability has declined in elderly population, but conflicting results exist about the trend for more severe stages [1] and the overall prevalence remains very high: 20 percent of older US adults have chronic disabilities.

Fortunately, older age is not uniformly associated with decline of performance [2], indicating the potential for effective interventions to promote more successful aging. The results of the few intervention programs designed to prevent functional decline in older people show that participants with relatively good functional status or moderate frailty are those who benefit the most of these programs [3], suggesting that interventions targeted early in the process of functional decline is potentially very effective. A concept of "frail subjects" is sometime used to define this target population [4]. Until now only minor attention has been paid to primary prevention of progressive disability among non-disabled old people. It seems useful to better characterize this early state of physical frailty associated with later disability.

However, many risk factors are involved in the disability process [5] and thus, a valid estimation of the weight of each factor is not straightforward. Most of the results are issued from cross-sectional studies whereas longitudinal studies are far more informative. But the analysis of repeated outcomes with possible recovery throughout time requires the use of non classical models that have only recently become available in statistical packages.

The first aim of this study is to identify the most important baseline predictors of the decline in instrumental activities of daily living (IADL) during a seven-year follow-up in a group of non-disabled women aged 75 years and over. 
The second aim is to devise an indicator of physical frailty in order either to select healthy women at risk of becoming disabled within the next few years and liable to benefit from an intervention program, or to evaluate the global risks in populations.

\section{MATERIALS AND METHODS}

\section{Subjects}

This article is based on a cohort of 545 high-functioning women aged 75 years and older, selected from 1547 women recruited in Montpellier, one of the five participating centers of the French EPIDOS study on the risk of hip fracture [6]. In this center the follow-up was extended to seven years. To ensure that the selected women have not already begun the IADL disability process, we considered only those independent in IADL both at inclusion and at the first year of follow-up (i.e.: performing light or heavy housework, laundry, shopping for groceries or personal items, preparing meals, using a telephone, taking public transport, managing money and taking medication without assistance) [7].

In addition the data from the EPIDOS center of Toulouse were used to test the predictive value of our indicator. This independent sample consisted of 807 women free of disability at inclusion and followed-up for four years.

\section{Baseline Evaluation}

The baseline evaluation was done in the local clinical center by trained doctors and nurses, and included a questionnaire, a physical examination, a functional assessment, and measurements of whole body bone mineral density (BMD) and body composition with lean mass (bone mineral excluded) and fat mass.

Educational level was assessed by a dichotomous variable: obtaining or not the old French Certificate of Elementary Education generally taken at the age of 14 years. 
Current physical activity was estimated by questions concerning physical exercise (walking, gymnastics, cycling, swimming, gardening), and heavy housework. The time spent for each activity was converted into metabolic equivalent (MET) by week and then the overall total was calculated.

Physical performance was assessed by a series of standard tests: quantitative measurements of grip and quadriceps strength and calf circumference; time taken to stand up and sit down five times with arms across the chest (chair stands); time taken to tap one foot back and forth ten times between two circles placed $30 \mathrm{~cm}$ apart in a sitting position (foot tapping); subjects were asked twice to walk six meters at normal pace to determine gait speed and step length. Standing balance was assessed by timed maintenance of the balance in progressively more challenging positions: side-by-side position, semi tandem position, and tandem position. Dynamic balance was assessed by testing the ability to walk with the heel of the front foot touching the big toe of the rear foot (tandem walk).

Corrected binocular visual acuity was measured at a distance of five meters with a Snellen letter test chart (decimal scale).

\section{Outcome Variable}

Every year, women filled out a mail questionnaire in which they were asked whether they were able to do the eight basic IADL without assistance. Women were scored on a dependence scale equivalent to the number of activities for which they needed assistance. Our variable of interest is a repeated binary outcome taking the value one if the yearly IADL score is positive and otherwise zero. Other cut-off points (score $\geq$ two and score $\geq$ three) were also investigated to check if the same risk factors were found again.

\section{Statistical Analysis}


The analysis includes six steps: 1) the sample was described and compared to the group of women with no IADL evaluation during the follow-up or missing data for at least one baseline covariable, using Student's t-test or Wilcoxon's test for quantitative variables and Chi square test for qualitative variables; 2) a comprehensive analysis was carried out in order to identify the baseline factors linked to the outcome variable of IADL decline. Every potential factor was tested in a univariate model, adjusted on time since inclusion and age at inclusion. 3) Predictors that were significant in the previous step were grouped into categories according to their source and availability in a typical clinical setting. Five categories of factors were used in our analysis: mobility, standing and dynamic balance, grip and quadriceps strength, body composition, perceived health. Several factors were not grouped: self-reported physical activity, visual acuity, educational level and body mass index (BMI) change since the age of 30 years. The predictors within each category were entered groupwise into a multivariate model. 4) The remaining significant predictors from each model were entered into a global multivariate model and the final selection of the covariables was done using a descending step by step method. 5) The regression coefficients of the final model were scaled and rounded to integers to create a score easy to implement. Optimal scaled and rounded coefficients were calculated using the algorithm proposed by Cole [8]. This algorithm consists in finding the smallest common multiplier, $\mathrm{k}$, which permits each estimated coefficient to be transformed into an integer without too much loss of precision. 6) The predictive value of this new scoring system was evaluated using the set of data provided by the EPIDOS center of Toulouse. The performance of this prognostic score was assessed using the c-statistic that is identical to the area under the receiver operator characteristic curve in the case of a binary outcome [9]. This statistic was calculated on the overall repeated observations throughout the 7 years of follow-up.

In longitudinal studies, the within subject responses (IADL) are correlated. This correlation was accounted for by using an extension of the logistic regression, the random-effect model 
[10]. The justification for applying this model to our data is extensively discussed in [11].

Briefly, this model has two basic characteristics: (i) subjects with incomplete responses across time are included in the analysis, (ii) subjects do not have to be measured at the same time points. In particular, the subjects who died during the seven years of follow-up are included in the analysis until the date of their death. This model allows the within-subjects dependency to vary from a subject to another, by the means of the random part $\left(\mathrm{u}_{\mathrm{i}}\right)$ of the covariables linear combination.

Let $Y_{i j}$ denote the binary outcome (IADL $>0$ ) corresponding to the $j$ th response (jth year in the study, $j=1$ to 7 ), evaluated at the time $t_{i j}$, of the $i$ th subject ( $i=1$ to 545 ). Let also $X_{i k}$ be the baseline covariates ( $k=1$ to $p$ ). The estimated model is :

$$
\operatorname{Logit}\left(P\left(Y_{i j}=1 / t_{i j}, X_{i k}, u_{i}\right)\right)=\alpha_{0}+\alpha_{1} t_{i j}+\alpha_{2} \operatorname{age}+\alpha_{3}\left(a g e * t_{i j}\right)+\sum_{k=1}^{p} \beta_{k} X_{i k}+u_{i}
$$

The parameters $\alpha_{0}, \alpha_{1}, \alpha_{2}, \alpha_{3}, \beta_{k}$ 's are common to all the subjects, while the $\mathrm{u}_{\mathrm{i}}$ 's are individual parameters of propensity to become disabled, constant through time. The scaled rounded coefficients of the final scoring system (step 5 of the analysis) are provided by multiplying the estimated parameters, $\alpha_{1}, \alpha_{2}, \alpha_{3}, \beta_{k}$ 's, by the optimal scaling multiplier, $\mathrm{k}$, and rounding them to the nearest integers. The SAS procedure NLMIXED was used to estimate the parameters. The final multivariate model was validated with the WinBUGS statistical software [12]. The quartile values of each quantitative potential risk factor were determined, thus forming three groups: lower quartile, middle quartiles and higher quartile. This categorization makes it possible to compare the odds ratio between the predictive factors to be compared.

\section{RESULTS}

Among the 691 women free of disability at inclusion and year one, data for at least one baseline factor were missing for 146 subjects; the final analysis thus includes 545 women. 
Subjects are described in table 1. A significant difference in age was found between the 545 selected women and the 146 excluded women. The women included in the analysis were younger (median age of 79 years compared to 80 years in the excluded group, $p<0.005$ ). Most of them (92.7 percent) lived at home.

The proportion of women reporting disability (table 2) increased from 22.1 percent at the end of the second year to 52.1 percent at the end of the seventh year. During the seven years, recovery from disability - that is an IADL score going back to zero - was observed at least once in 155 women (28.4 percent). Some women gave intermittent answers. For example, among the 432 women still providing a response at year seven, 83 women (19.2 percent) had at least one observation missing in the previous years. The actual time between yearly assessments and inclusion varied from one woman to another and the range tended to be higher at the end of the follow-up. Consequently, time is considered as a continuous covariable in the subsequent models. Vital status was known throughout the seven years for all the participants, even for those who no longer sent back the questionnaires. The total number of deaths was 63 (11.6 percent) by the end of the study.

Tables 3a and 3b give the univariate odds ratios (OR) and the 95 percent confidence intervals (95\%CI) for all the predictive factors significantly related to disability defined by a positive IADL score. The predictors are presented according to the groups of pre-selection for the final model. Twenty-one factors were found to be significantly associated with disability. The final multivariate model is presented in table 4 with the risk factors in the order of importance. The parameters and the odds ratios corresponding to the time since inclusion, interaction age *time and nine remaining significant risk factors are given. For three covariables (gait speed, physical activity and BMI), the middle category was removed from the final model since its parameter was very close to zero. 
Concerning the predictors measured at baseline, the strongest belonged to the "mobility" group. Compared to the quartile of best performances, the odds ratio (95\%CI) corresponding to lower performances was equal to $7.62(3.86,15.04), 6.31(3.26,12.19)$ and $5.31(2.43$, 11.59) for, respectively, time to complete five chair stands, gait speed and number of steps to walk six meters. In the multivariate model the first two remained significant. In second place, the group of balance tests (ten foot taps, standing in tandem position and tandem walk) was also very important but in the multivariate model the ability to stand in tandem position was the most discriminating. At last, the group "body composition" was also predictive, with measures such as BMI, relative fat mass being very significant in the univariate model. In the final model, BMI seems the best measure of body composition for predicting disability. Both the grip and quadriceps strength were significant in the univariate analysis but only the grip strength remains in the final model.

Concerning the factors collected by the questionnaire, the group "perceived health" was particularly noteworthy, with two variables remaining in the final model: self-rated health and fear of falling. Declared physical activity and educational level were also very significant. The algorithm calculating a simpler score from the final model, leads to an optimal scaling multiplier (k), unique and equal to 16.44 (table 4). For a given woman, the score predicting functional dependence is easily provided by summing the scaled rounded coefficients for her observed risk factors (Cf. appendix).

The predictive value of this score was evaluated using the same sample of 545 women observed for seven years and the independent sample of 807 women included by the Epidos center of Toulouse. The c-statistic was equal respectively to 0.72 and 0.71 , indicating a good level of prediction. 


\section{DISCUSSION}

\section{Relevant Targeted Population}

Our study is limited to women aged 75 years or over. This segment of the population represents an interesting target for intervention. Women represent the largest proportion of the elderly and their patterns of functional decline seem to be different from the men. Concerning light disability measured with the IADL indicator and lower body physical ability score, it is suggested that if incidence rates are roughly equal in both genders, the prevalence rates are higher in women, indicating a longer time spent in disability. This is consistent with several studies demonstrating that both recovery and death rates are lower for women than for men [13]. Women with light disability seem to outlive men from 75 to 85 years to the oldest ages, and for that reason they are at higher risk of developing severe disability in the very old ages [14].

In the age group of our study the life expectancy is still high (13 and 6.5 years for respectively the 75 and 85 year old French women). However as functional decline had begun among some subjects we needed to select a sample of women free of disability for two consecutive years to ensure that we studied incident disability only. Our high-functioning sample is therefore closer to a younger age group. Further studies are necessary to define the age class in which the screening of at risk subjects would be the most cost-effective. This optimal age interval is likely to be between 65 and 75 years but it will tend to shift upwards with increase in life expectancy.

\section{Definition of disability onset}

Several instruments are currently used to assess functional limitation. Since our purpose was to predict the early stage of dependency, the IADL scale was preferred. Wolinsky et al. [15] showed that deterioration in IADL functioning is a strong predictor of future decline. This outcome seems more suitable to our goal than the Katz's ADL scale that was demonstrated to only capture disability at the extreme end of the process and to be thus unable to discriminate 
levels of disability in community populations where the prevalence of ADL disability tends to be low [16].

The loss of IADL has both a cognitive and motor origin [17]. In particular complex activities (handling money, phone use, self-medication) were demonstrated to be correlated with cognitive impairment [18]. Our score is therefore predictive of global disability including cognitive impairment.

\section{Powerful Fitting Method}

One of the strengths of this study is the longitudinal design with outcomes measured yearly over a seven-year period with minimal loss to follow-up. Even though our sample is not very large ( $n=545)$, the number of repeated evaluations by subject and the use of a powerful model allow us to detect numerous risk factors. To our knowledge it is the first time that a random effect model for binary responses is used to predict disability in elderly people. The statistical methods (Cox models) analyzing the time to disability onset cannot be used, as the proportion of women who reverse from disability (28 percent) is very high. Several authors $[19,20]$ used random effect models or generalized estimating equations (GEE) models but they considered the outcome as a normally distributed response. In general the scores measuring disability are finite ordinal scales, positively skewed, and they cannot be considered as quantitative.

Compared to GEE, we advocated [11] that the random effect model for binary response is more suitable and has interesting advantages.

\section{Hierarchy Between The Frailty Components}

Firstly, our statistical analysis modeled the impact of time on disability occurrence. Every additional year brings a marked increase in the probability of being dependent. Moreover we found an interaction between age at entry and time: the risk of disability is accelerated in the oldest women.

Our final model also gives the relative weight of baseline risk factors in predicting disability during the following seven years. This combination of predictors may be seen as a physical 
frailty score. Physical frailty was defined as a physiological state of increased vulnerability to stressors that results from decreased physiological reserves of multiple physiological systems $[21,22]$. In community dwelling people this frailty state is often asymtomatic because the individuals use high compensatory strategies. This instable equilibrium can be easily broken by minimal environmental challenges.

Clinical experts and geriatricians have proposed various criteria for defining frailty. Campbell et al [23] defined frailty as a loss of the person's capability to withstand minor environmental stresses and suggested four essential reserve capacities: musculoskeletal function, aerobic capacity, cognitive function and nutritional state. Fried et al [24] introduced the concept of "frailty syndrome" based on five domains: nutrition (loss of weight), muscle strength (grip test), endurance (exhaustion), mobility (walking speed) and physical activity. During the last decade, three other domains have often been cited in the literature: balance, motor processing (speed of movement, coordination) and cognition [4,25].

Our large screening of potential factors in a prospective study confirms the important role of five of these dimensions and establishes the following hierarchy: mobility (gait speed and chair stand), balance (tandem position test), nutrition (BMI), muscle strength (grip test) and physical activity. We also found a marked impact of perceived health (self-rated health and fear of falling) on the probability of becoming dependent. Several authors also found an association of perceived health with mortality [26], or chronic conditions [27], or functional capacity loss [28], or physical inactivity [29]. But, except for mortality, this association was demonstrated in cross-sectional studies and interpreted as a consequence of physical deterioration. In contrast, our findings suggest that poor perceived health increases the risk of later physical limitations. At last, women with low educational level were found to be significantly more at risk of becoming disabled. This finding is supported by other results [30]. Low educational level may be interpreted as a proxy for characteristics such as low income or adverse life conditions or limited access to prevention programs. 
The nutritional dimension of the frailty syndrome is usually defined as a shrinking process and identified by a low body weight or a lean mass loss [24]. By contrast, in the univariate analysis we found a positive association between the risk of disability and body weight, BMI, fat body mass and gain of weight from the age of 30 years. The prospective work of Launer et al [31] suggests that high BMI and weight loss are risk factors for decreased mobility in elderly women. In our cohort there are few women with low BMI. Further studies are needed to identify the mechanism through which BMI may affect disability and to test whether the J shaped risk curve found for the relation between BMI and mortality [32] is also relevant here, particularly in later functional dependence.

In the Epidos cohort cognitive impairment was not evaluated at inclusion and therefore this domain is not present in our final score. However in this highly selected group, no diagnosis of moderate or severe dementia was reported at baseline and cognitive impairment if present is likely to be mind.

In our analysis, risk factors such as history of depression, heart disease, cancer or body mass density, were not found to be predictive of disability in contradiction with some crosssectional analyses [33]. This finding suggests that functional performance tests are more relevant for evaluating reserve capacities than screening of chronic diseases. Similarly variables concerning baseline food intakes were also non significant in our cohort but the questionnaire focused mainly on calcium intake and probably lacked exhaustiveness.

\section{Applicability of the Predictive Score}

We present a predictive score using an integer-based linear combination of risk factors. The

good correspondence between the predicted and observed disability status in an independent sample suggests that the scale can provide accurate risk evaluation. However it may be worthwhile to validate our score by measuring the misclassification rate in new cohorts of subjects. 
An important requirement for the practical use of a predictive score is its simplicity in order to ensure its applicability in various settings. Fortunately the selected predictors in the final model are very simple to collect. They are a combination of self-reported data and objective measures particularly easy to implement, even by non-clinical health care workers. Furthermore scaling and rounding equation coefficients to integers contributes to this simplicity.

Our study attempts to quantify physical frailty viewed as a physiological precursor of disability. The predictive score computed thus has considerable practical value for clinicians and public health professionals: it can be used to select subjects apparently in good health but who are at risk of becoming disabled and to which can then be recommended a well-designed physical training program in order to postpone dependence.

\section{ACKNOWLEDGEMENTS}

The authors are grateful to Dr Hélène Grandjean and the unit INSERM U558, who provided the data from the Toulouse EPIDOS center and to Annie Lacroux for editorial assistance. 


\section{REFERENCES}

1. Freedman VA, Martin LG, Schoeni RF. Recent trends in disability and functioning among older adults in the United States: a systematic review. JAMA 2002;288:3137-3146.

2. Seeman TE, Charpentier PA, Berkman LF, et al. Predicting changes in physical performance in a high-functioning elderly cohort: MacArthur studies of successful aging. J Gerontol 1994;49:M97-108.

3. Gill TM, Baker DI, Gottschalk M, et al. A program to prevent functional decline in physically frail, elderly persons who live at home. N Engl J Med 2002;347:1068-1074.

4. Ferrucci L, Guralnik JM, Studenski S, et al. Designing randomized, controlled trials aimed at preventing or delaying functional decline and disability in frail, older persons: a consensus report. J Am Geriatr Soc 2004;52:625-634.

5. Stuck AE, Walthert JM, Nikolaus T, et al. Risk factors for functional status decline in community-living elderly people: a systematic literature review. Soc Sci Med 1999;48:445-469.

6. Dargent-Molina P, Favier F, Grandjean H, et al. Fall-related factors and risk of hip fracture: the EPIDOS prospective study. Lancet 1996;348:145-149.

7. Lawton MP, Brody EM. Assessment of older people: self-maintaining and instrumental activities of daily living. Gerontologist 1969;9:179-186.

8. Cole TJ. Scaling and rounding regression coefficients to integers. Appl Stat 1993;42:261268.

9. Harrell Fe JR, Lee KL, Califf RM, et al. Regression modelling strategies for improved prognostic prediction. Stat Med 1984;3:143-152.

10. Diggle PJ, Liang KY, Zeger SL. Analysis of longitudinal data. Oxford: Oxford Science Publications;1994. 
11. Carriere I, Bouyer J. Choosing marginal or random-effects models for longitudinal binary responses: application to self-reported disability among older persons. BMC Med Res Methodol 2002;2:15.

12. Spiegelhalter DJ, Thomas A, Best NG, et al. BUGS: Bayesian Inference Using Gibbs Sampling, Version 5.0, (version ii). MRC Biostatistics Unit, Cambridge, 1996.

13. Oman D, Reed D, Ferrara A. Do elderly women have more physical disability than men do? Am J Epidemiol 1999;150:834-842.

14. Von Strauss E, Aguero Torres H, Kareholt I, et al. Women are more disabled in basic activities of daily living than men only in very advanced ages: a study on disability, morbidity, and mortality from the Kungsholmen Project. J Clin Epidemiol 2003;56:669677.

15. Wolinsky FD, Johnson RJ. The use of health services by older adults. J Gerontol 1991;46:S345-S357.

16. Kovar MG, Lawton P. Activities and instrumental activities of daily living. Ann Rev Geriat Gerontol 1994;14:57-75.

17. Thomas VS, Rockwood K, McDowell I. Multidimensionality in instrumental and basic activities of daily living. J Clin Epidemiol 1998;51:315-321.

18. Barberger-Gateau P, Commenges D, Gagnon M, et al. Instrumental activities of daily living as a screening tool for cognitive impairment and dementia in elderly community dwellers. J Am Geriatr Soc 1992;40:1129-34.

19. Beckett LA, Brock DB, Lemke JH, et al. Analysis of change in self-reported physical function among older persons in four population studies. Am J Epidemiol 1996;143:766778.

20. Dunlop DD, Hughes SL, Edelman P, et al. Impact of joint impairment on disabilityspecific domains at four years. J Clin Epidemiol 1998;51:1253-1261. 
21. Fried LP, Ferrucci L, Darer J, et al. Untangling the concepts of disability, frailty, and comorbidity: implications for improved targeting and care. J Gerontol A Biol Sci Med Sci 2004;59:255-263.

22. Bortz Wm 2ND. A conceptual framework of frailty: a review. J Gerontol A Biol Sci Med Sci 2002;57:M283-M288.

23. Campbell AJ, Buchner DM. Unstable disability and the fluctuations of frailty. Age Ageing 1997;26:315-318.

24. Fried LP, Tangen CM, Walston J, et al. Frailty in older adults: evidence for a phenotype. J Gerontol A Biol Sci Med Sci 2001;56:M146-M156.

25. Studenski S, Hayes RP, Leibowitz RQ, et al. Clinical Global Impression of Change in Physical Frailty: development of a measure based on clinical judgment. J Am Geriatr Soc 2004;52:1560-1566.

26. Yu ES, Kean YM, Slymen DJ, et al. Self-perceived health and 5-year mortality risks among the elderly in Shanghai, China. Am J Epidemiol 1998;147:880-890.

27. Hoeymans N, Feskens EJ, Kromhout D, et al. The contribution of chronic conditions and disabilities to poor self-rated health in elderly men. J Gerontol A Biol Sci Med Sci 1999;54:M501-M506.

28. Jylha M, Guralnik JM, Balfour J, et al. Walking difficulty, walking speed, and age as predictors of self-rated health: the women's health and aging study. J Gerontol A Biol Sci Med Sci 2001;56:M609-M617.

29. Chin A Paw MJ, Dekker JM, Feskens EJ, et al. How to select a frail elderly population? A comparison of three working definitions. J Clin Epidemiol 1999;52:1015-1021.

30. Manton KG, Stallard E, Corder L. Education-specific estimates of life expectancy and age-specific disability in the U.S. elderly population: 1982 to 1991. J Aging Health 1997;9:419-450. 
31. Launer LJ, Harris T, Rumpel C, et al. Body mass index, weight change, and risk of mobility disability in middle-aged and older women. The epidemiologic follow-up study of NHANES I. JAMA 1994;271:1093-1098.

32. Calle EE, Thun MJ, Petrelli JM, et al. Body-mass index and mortality in a prospective cohort of U.S. adults. N Engl J Med 1999;341:1097-1105.

33. Nourhashemi F, Andrieu S, Gillette Guyonnet S, et al. Instrumental activities of daily living as a potential marker of frailty: a study of 7364 community-dwelling elderly women (the EPIDOS study). J Gerontol A Biol Sci Med Sci 2001;56:M448-M453. 
TABLE 1: Comparison of women included in the analysis versus those excluded because of missing data

\begin{tabular}{lccc}
\hline \multicolumn{1}{c}{ Parameters } & $\begin{array}{c}\text { Included in the analysis } \\
(\mathrm{n}=545)\end{array}$ & $\begin{array}{c}\text { With missing data } \\
(\mathrm{n}=146)\end{array}$ & p value* \\
\hline Age in years [median (IQR)] & $79(76-81)$ & $80(77-82)$ & $<0.005$ \\
Body mass index in $\mathrm{kg} / \mathrm{m}^{2}$ [mean (SD)] & $25.2(3.8)$ & $25.9(4.0)$ & 0.05 \\
Comparative health (\%) & & & \\
$\quad$ Healthier & 43.3 & 34.1 & \\
$\quad$ As healthy & 55.0 & 65.9 & \\
$\quad 1.7$ & 0.0 & 0.04 \\
Less healthy & 92.7 & 95.2 & 0.22 \\
Living at home (\%) & 46.8 & 43.0 & 0.41 \\
Hospitalized during the previous year (\%) & 15.6 & 18.6 & 0.38 \\
History of cancer (\%) & 19.8 & 21.9 & 0.57 \\
History of cardiovascular disease (\%) & 26.4 & 23.3 & 0.44 \\
History of depression (\%) & 0.9 & 2.1 & 0.38 \\
\hline
\end{tabular}

*Wilcoxon's test, or Student $t$-test, or Chi 2 test, or Fisher's exact test. 
TABLE 2: Description of the data by year of assessment $(n=545)$

\begin{tabular}{|c|c|c|c|c|c|c|}
\hline & Year 2 & Year 3 & Year 4 & Year 5 & Year 6 & Year 7 \\
\hline $\begin{array}{l}\text { Number of women with } \\
\text { disability assessment }\end{array}$ & 542 & 525 & 498 & 438 & 413 & 432 \\
\hline $\begin{array}{l}\text { Number of deaths for the } \\
\text { preceding year }\end{array}$ & 1 & 8 & 15 & 13 & 15 & 11 \\
\hline $\begin{array}{l}\text { Number of women without } \\
\text { disability assessment }\end{array}$ & 2 & 11 & 23 & 70 & 80 & 50 \\
\hline \multicolumn{7}{|l|}{ Percent of disabled women } \\
\hline IADL $>0$ & 22.1 & 27.4 & 33.7 & 36.3 & 42.4 & 52.1 \\
\hline IADL $>1$ & 10.0 & 10.7 & 18.1 & 17.8 & 27.9 & 33.8 \\
\hline IADL $>2$ & 5.4 & 5.7 & 10.2 & 12.1 & 19.4 & 24.1 \\
\hline \multicolumn{7}{|l|}{ Time since inclusion (years) } \\
\hline Median & 1.98 & 2.97 & 3.94 & 4.96 & 6.06 & 6.99 \\
\hline Range & $1.95-2.37$ & $2.95-3.26$ & $3.90-4.26$ & 4.89-5.89 & $5.92-6.87$ & $6.91-7.59$ \\
\hline
\end{tabular}


TABLE 3a: Univariate models, time and age-adjusted odds-ratios

\begin{tabular}{|c|c|c|}
\hline & Odds-ratio & 95\% Confidence Interval \\
\hline \multicolumn{3}{|l|}{ MOBILITY } \\
\hline \multicolumn{3}{|l|}{ Gait speed (m/sec) } \\
\hline$<0.78$ & $6.31^{* * * *}$ & $3.26,12.19$ \\
\hline $0.78-1.0$ & $2.32^{* *}$ & $1.32,4.08$ \\
\hline$\geq 1.0$ & 1 & \\
\hline \multicolumn{3}{|l|}{ Number of steps to walk $6 \mathrm{~m}$} \\
\hline$<11$ & 1 & \\
\hline $11-13$ & 1.01 & $0.50,2.05$ \\
\hline$\geq 13$ & $5.31^{* * * *}$ & $2.43,11.59$ \\
\hline \multicolumn{3}{|l|}{ Time to complete five chair stands (sec) } \\
\hline$<9.6$ & 1 & \\
\hline $9.6-13$ & $2.35^{* *}$ & $1.30,4.24$ \\
\hline$\geq 13$ & $7.62^{* * * *}$ & $3.86,15.04$ \\
\hline \multicolumn{3}{|l|}{ BALANCE } \\
\hline \multicolumn{3}{|l|}{ Time to complete 10 foot taps (sec) } \\
\hline$<4.25$ & 1 & \\
\hline $4.25-6.6$ & $2.05^{*}$ & $1.14,3.67$ \\
\hline$\geq 6.6$ & $5.35^{* * * *}$ & $2.75,10.43$ \\
\hline \multicolumn{3}{|l|}{ Time to stand in tandem position (sec) } \\
\hline 0 & $6.07^{* * * *}$ & $2.86,12.88$ \\
\hline $0.1-5$ & 1.74 & $1.00,3.01$ \\
\hline$\geq 5$ & 1 & \\
\hline \multicolumn{3}{|l|}{ Difficulty in performing a tandem walk } \\
\hline Able to do 4 consecutive tandem steps & 1 & \\
\hline Unable without stepping off & 1.27 & $0.74,2.17$ \\
\hline Unable & $8.36^{* * *}$ & $2.70,25.91$ \\
\hline \multicolumn{3}{|l|}{ STRENGTH } \\
\hline \multicolumn{3}{|l|}{ Grip strength (Kpa) } \\
\hline$<47$ & $2.81^{* *}$ & $1.43,5.52$ \\
\hline $47-61$ & 1.36 & $0.77,2.40$ \\
\hline$\geq 61$ & 1 & \\
\hline \multicolumn{3}{|l|}{$\begin{array}{l}\text { Quadriceps strength (Newton/lower leg length in } \\
\mathrm{cm} \text { ) }\end{array}$} \\
\hline 3.52 & $2.69^{* *}$ & $1.38,5.24$ \\
\hline $3.52-4.95$ & 1.50 & $0.85,2.66$ \\
\hline$\geq 4.95$ & 1 & \\
\hline \multicolumn{3}{|l|}{ Visual acuity } \\
\hline$\leq 4$ & 1.77 & $0.97,3.26$ \\
\hline$>4$ & 1 & \\
\hline $\begin{array}{l}{ }^{*} \mathrm{p}<0.05 \\
{ }^{* * *} \mathrm{p}<0.01 \\
{ }^{* * *} \mathrm{p}<0.001 \\
{ }^{* * * *} \mathrm{p}<0.0001\end{array}$ & & \\
\hline
\end{tabular}


TABLE 3b: Univariate models, time and age-adjusted odds-ratios

\begin{tabular}{|c|c|c|}
\hline & Odds-ratio & 95\% Confidence Interval \\
\hline \multicolumn{3}{|l|}{ BODY COMPOSITION } \\
\hline \multicolumn{3}{|l|}{ Weight (kg) } \\
\hline$<53$ & 1 & \\
\hline $53-65$ & 0.94 & $0.52,1.70$ \\
\hline$\geq 65$ & $2.02^{*}$ & $1.02,3.98$ \\
\hline \multicolumn{3}{|l|}{ Lean mass/body mass } \\
\hline$<0.54$ & 1 & \\
\hline $0.54-0.63$ & $0.45^{* *}$ & $0.25,0.80$ \\
\hline$\geq 0.63$ & $0.35^{* *}$ & $0.18,0.69$ \\
\hline \multicolumn{3}{|l|}{ Fat mass/body mass } \\
\hline$<0.31$ & 1 & \\
\hline $0.31-0.40$ & 1.09 & $0.61,1.93$ \\
\hline$\geq 0.40$ & $2.87^{* *}$ & $1.52,5.42$ \\
\hline \multicolumn{3}{|l|}{ Boby mass index $\left(\mathrm{kg} / \mathrm{m}^{2}\right)$} \\
\hline$<22.8$ & 1 & \\
\hline $22.8-27.6$ & 0.87 & $0.49,1.54$ \\
\hline$\geq 27.6$ & $2.97^{* *}$ & $1.55,5.70$ \\
\hline \multicolumn{3}{|l|}{ Waist/hip circumference } \\
\hline$<0.81$ & 1 & \\
\hline $0.81-0.90$ & 1.40 & $0.79,2.48$ \\
\hline$\geq 0.90$ & 1.82 & $0.93,3.58$ \\
\hline \multicolumn{3}{|c|}{ Weight change from the age of 30 yrs $(\mathrm{kg})$} \\
\hline$<0$ & 1 & \\
\hline $0-12$ & 1.02 & $0.56,1.85$ \\
\hline$\geq 12$ & $2.02^{*}$ & $1.02,4.02$ \\
\hline \multicolumn{3}{|c|}{ BMI change from the age of $30 \mathrm{yrs}\left(\mathrm{kg} / \mathrm{m}^{2}\right)$} \\
\hline$<2$ & 1 & \\
\hline $2-7$ & 1.10 & $0.62,1.95$ \\
\hline$\geq 7$ & $2.15^{*}$ & $1.09,4.24$ \\
\hline \multicolumn{3}{|c|}{ Physical activity (MET/week) } \\
\hline$<6.9$ & $3.53^{* * *}$ & $1.78,7.01$ \\
\hline $6.9-36.6$ & 1.58 & $0.90,2.79$ \\
\hline$\geq 36.6$ & 1 & \\
\hline \multicolumn{3}{|l|}{ Educational level } \\
\hline Primary school & $2.33^{* * *}$ & $1.46,3.72$ \\
\hline$>$ primary school & 1 & \\
\hline \multicolumn{3}{|l|}{ PERCEIVED HEALTH } \\
\hline \multicolumn{3}{|l|}{ Self-rated health } \\
\hline Bad or very bad & $7.26^{* *}$ & $2.01,26.25$ \\
\hline Good or very good & 1 & \\
\hline \multicolumn{3}{|c|}{ Compared health / women of same age } \\
\hline As or less healthy & $2.42^{* * *}$ & $1.51,3.90$ \\
\hline Healthier & 1 & \\
\hline \multicolumn{3}{|l|}{ Fear of falling } \\
\hline Yes & $2.57^{* * * *}$ & $1.61,4.12$ \\
\hline No & 1 & \\
\hline $\begin{array}{l}{ }^{*} \mathrm{p}<0.05 \\
{ }^{* *} \mathrm{p}<0.01 \\
{ }^{* * *} \mathrm{p}<0.001 \\
{ }^{* * * *} \mathrm{p}<0.0001\end{array}$ & & \\
\hline
\end{tabular}


TABLE 4: Multivariate model and the derived simplified model (with rounded/scaled coefficients)

\begin{tabular}{|c|c|c|c|c|}
\hline & \multicolumn{3}{|c|}{ Final model } & \multirow{2}{*}{$\begin{array}{c}\text { Scaled and } \\
\text { rounded } \\
\text { coefficient } \\
(\mathrm{k}=16.44)^{*}\end{array}$} \\
\hline & Parameter & Odds-ratio & $\begin{array}{l}\text { 95\% Confidence } \\
\text { Interval } \\
\end{array}$ & \\
\hline Time since baseline evaluation (years) & 0.38 & 1.46 & $1.33,1.60$ & 6 \\
\hline Age $^{\dagger *}$ Time since baseline evaluation & 0.03 & 1.03 & $1.02,1.05$ & 1 \\
\hline $\begin{array}{l}\text { MOBILITY } \\
\text { Gait speed (m/sec) }\end{array}$ & & & & \\
\hline$<0.78$ & 0.57 & 1.76 & $1.04,2.98$ & 9 \\
\hline $\begin{array}{l}\text { Time to complete five chair stand (sec) } \\
\begin{array}{l}9.6-13 \\
\geq 13\end{array}\end{array}$ & $\begin{array}{l}0.48 \\
1.23 \\
\end{array}$ & $\begin{array}{l}1.61 \\
3.41 \\
\end{array}$ & $\begin{array}{l}0.92,2.82 \\
1.74,6.67 \\
\end{array}$ & $\begin{array}{c}8 \\
20 \\
\end{array}$ \\
\hline $\begin{array}{l}\text { PERCEIVED HEALTH } \\
\text { Self-rated health }\end{array}$ & & & & \\
\hline $\begin{array}{l}\text { Bad or very bad } \\
\text { Fear of falling } \\
\end{array}$ & $\begin{array}{l}1.25 \\
0.46 \\
\end{array}$ & $\begin{array}{l}3.47 \\
1.58 \\
\end{array}$ & $\begin{array}{c}1.07,11.33 \\
1.01,2.46 \\
\end{array}$ & $\begin{array}{c}20 \\
7\end{array}$ \\
\hline $\begin{array}{l}\text { BALANCE } \\
\text { Time to stand in tandem position (sec) }\end{array}$ & & & & \\
\hline $\begin{array}{l}0 \\
0.1-5 \\
\end{array}$ & $\begin{array}{l}1.11 \\
0.33 \\
\end{array}$ & $\begin{array}{l}3.04 \\
1.39 \\
\end{array}$ & $\begin{array}{l}1.49,6.21 \\
0.83,2.34 \\
\end{array}$ & $\begin{array}{c}18 \\
5 \\
\end{array}$ \\
\hline $\begin{array}{l}\text { NUTRITION } \\
\text { Boby mass index }\left(\mathrm{kg} / \mathrm{m}^{2}\right)\end{array}$ & & & & \\
\hline$\geq 27.6$ & 0.89 & 2.43 & $1.48,3.98$ & 15 \\
\hline $\begin{array}{l}\text { MUSCLE STRENGTH } \\
\text { Grip strength (Kpa) }\end{array}$ & & & & \\
\hline $\begin{array}{l}<47 \\
\geq 47\end{array}$ & $\begin{array}{c}0.58 \\
1 \\
\end{array}$ & 1.78 & $1.07,2.95$ & 9 \\
\hline $\begin{array}{l}\text { Physical activity (MET/week) } \\
<6.9\end{array}$ & 0.51 & 1.67 & $0.99,2.82$ & 8 \\
\hline $\begin{array}{l}\text { Educational level } \\
\text { Primary school }\end{array}$ & 0.45 & 1.57 & $1.02,2.44$ & 7 \\
\hline
\end{tabular}

* k: scaling coefficient

$\dagger$ years over 74 
Appendix

\section{Score}

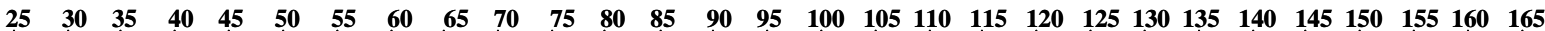

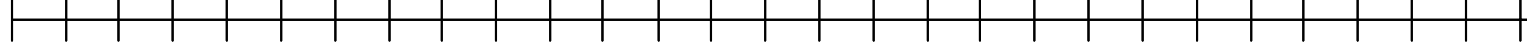

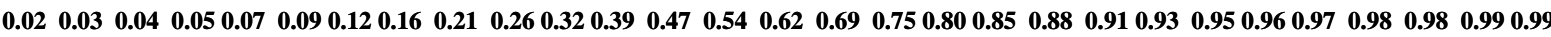

Risk

For example, a 78 years old woman, free of disability, with a grip strength $<47 \mathrm{Kpa}$, a BMI $\geq$ 27.6, bad self-rated health and who has fear of falling, will have, 3 years later, a score $=6 *(3$ years since baseline $)+(4$ years over 74 years old $* 3$ years since baseline $)+9$ (grip strength) $+15(\mathrm{BMI})+20$ (self-rated health) +7 (fear of falling) $=81$ which corresponds to a risk for dependency $=0.39$. 